\title{
Myxozoan hidden diversity: the case of Myxobolus pseudodispar Gorbunova, 1936
}

\author{
Martina Lisnerová ${ }^{1,2}$, Petr Blabolil ${ }^{3}$, Astrid Holzer ${ }^{1}$, Pavel Jurajda ${ }^{4}$ and Ivan Fiala ${ }^{1,2}$ \\ ${ }^{1}$ Institute of Parasitology, Biology Centre of the Czech Academy of Sciences, České Budějovice, Czech Republic; \\ ${ }^{2}$ Department of Parasitology, Faculty of Sciences, University of South Bohemia, České Budějovice, Czech Republic; \\ ${ }^{3}$ Institute of Hydrobiology, Biology Centre of the Czech Academy of Sciences, České Budějovice, Czech Republic; \\ ${ }^{4}$ Institute of Vertebrate Biology of the Czech Academy of Sciences, Brno, Czech Republic
}

\begin{abstract}
Myxobolus pseudodispar Gorbunova, 1936 (Myxozoa) was originally described as a parasite of common roach, Rutilus rutilus (Linnaeus), with developing stages in muscles and spores disseminated in macrophage centres of different organs and tissues. Later, this parasite was described from several other cyprinids, but with relatively large intraspecific differences based on SSU rDNA gene sequences. Within our long-term study on myxozoan biodiversity, we performed a broad microscopic and molecular screening of various freshwater fish species (over 450 specimens, 36 species) from different localities. We investigated the cryptic species status of M. pseudodispar. Our analysis revealed four new unique SSU rDNA sequences of M. pseudodispar as well as an infection in new fish host species. Myxobolus pseudodispar sequence analysis showed clear phylogenetic grouping according to fish host criterion forming 13 well-recognised clades. Using 1\% SSU rDNA-based genetic distance criterion, at least ten new species of Myxobolus Bütschli, 1882 may be recognised in the group of M. pseudodispar sequences. Our analysis showed the paraphyletic character of M. pseudodispar sequences and the statistical tests rejected hypothetical tree topology with the monophyletic status of the M. pseudodispar group. Myxobolus pseudodispar represents a species complex and it is a typical example of myxozoan hidden diversity phenomenon confirming myxozoans as an evolutionary very successful group of parasites with a great ability to adapt to a new hosts with subsequent speciation events.
\end{abstract}

Keywords: Myxozoa, phylogeny, PCR screening, cryptic species, host specificity.

This article contains supporting information (S1-S2) online at http://folia.paru.cas.cz/suppl/2020-67-019.pdf

Suplementary file 1 online at http://folia.paru.cas.cz/suppl/2020-67-019b.fasta

The Myxozoa is a diverse group of endoparasites with a worldwide distribution numbering more than 2,600 described species, which represents approx. $20 \%$ of cnidarians (Okamura et al. 2015, 2018). However, much of myxozoan biodiversity appears to be hidden (Bartošová-Sojková et al. 2014, Hartikainen et al. 2016). Their complex life cycle involves two hosts: invertebrates (Oligochaeta, Polychaeta and Bryozoa) as a definitive host, and vertebrates (mainly fish, rarely amphibians, reptiles, birds or mammals) as an intermediate host (Okamura et al. 2015). Myxozoan infections in fish are frequently inconspicuous; however, several myxozoans are highly pathogenic for their hosts causing whirling disease or proliferative kidney disease in salmonid fish (Hedrick et al. 1993, Gilbert and Granath 2003).
Myxobolus Bütschli, 1882 is the largest genus of the Myxozoa with more than 850 described species (Eiras et al. 2005, 2014). Species of Myxobolus have been reported from fish worldwide (e.g., Carriero et al. 2013, Lövy et al. 2018, Folefack et al. 2019). They infect mostly freshwater fish but they have been found also in brackish and marine hosts (e.g., Liu et al. 2019, Rocha et al. 2019). The diversity success of the Myxobolus is assumed to be caused by the shape of spores with lateral flattening that enabled easier invasion of tissues from precursors that lived in body liquids and cavities. Therefore, they could colonise many types of tissues (Fiala et al. 2015). Species of Myxobolus constitute the largest clade in the phylogenetic tree branching within the oligochaete-infecting lineage of myxozoans (Holzer et al. 2018). However, it is a paraphyletic taxon with Henneguya Thélohan, 1892; Thelohanellus Kudo,

Address for correspondence: Ivan Fiala, Biology Centre of ASCR, Institute of Parasitology, and Faculty of Science, University of South Bohemia, Branišovská 31, České Budějovice, 37005, Czech Republic. Phone: +420387775450; Fax.: +420385310388; E-mail: fiala@paru.cas.cz 
1933; Unicauda Davis, 1944; Cardimyxobolus Ma, Dong et Wang, 1982 and species of Hennegoides Lom, Tonguthai et Dyková, 1991 clustering with species of Myxobolus (see Fiala 2006, Liu et al. 2019).

The genus Myxobolus is morphologically characterised by ovoid or rounded spores with smooth shell valves and with two mostly pyriform, sometimes unequal polar capsules (Lom and Dyková 2006). Myxospore valve projections (appendages) typical for species of Henneguya, Unicauda and Hennegoides appeared or have been lost several times independently in myxobolid evolution (Liu et al. 2019) similarly as a loss of one of the polar capsules, the trait characteristic for species of the genus Thelohanellus (see Zhang et al. 2019).

It has been proved many times by phylogenetic analyses based on molecular data that molecular taxonomy of the genus Myxobolus and other myxozoan genera does not entirely reflect morphological similarities of myxozoan spores. Phylogenetic relationships rather correlate with host environment, host and host tissues preferences (Andree et al. 1999, Kent et al. 2001, Eszterbauer 2004, Fiala 2006, Fiala and Bartošová 2010, Holzer et al. 2018). Although a study by Salim and Desser (2000) demonstrated clustering of species of Myxobolus according to the morphology of the spores, analysis by Andree et al. (1999) and Eszterbauer (2004) reported relationships based on the site of infection. Host-associated phylogenetic pattern of Myxobolus spp. has been suggested by Carriero et al. (2013) as well as by Liu et al. (2019), who made a comprehensive analysis of all available sequences of SSU rDNA of Myxobolus spp.

Myxobolus pseudodispar Gorbunova, 1936 was originally described as a common myxozoan parasite of common roach (Rutilus rutilus [Linnaeus]) with developing stages in muscles and spores disseminated in macrophage centres of different organs and tissues. Since the original description, M. pseudodispar has been documented from different organs (gills, kidney, liver, muscle, skin and spleen) of many cyprinids e.g., Abramis brama (Linneaus); Alburnus alburnus (Linnaeus); Blicca bjoerkna (Linnaeus); Pseudochondrostoma polylepis (Steindachner); Squalius squalus (Bonaparte); Achondrostoma arcasii (Steindachner); Scardinius erythrophthalmus (Linnaeus) (Gorbunova 1936, Gonzalez-Lanza and Alvarez-Pellitero 1985, Baska 1987, Eszterbauer et al. 2001, Székely et al. 2001, Molnár et al. 2002).

Spores of M. pseudodispar are ovoid or rounded with an irregular shape. Unequal polar capsules are located laterally from the longitudinal axis of the spore, which is the character distinguishing $M$. pseudodispar from morphologically very similar Myxobolus dispar (Gorbunova 1936). Myxobolus pseudodispar was considered as a junior synonym of Myxobolus cyprini Doflein, 1898 because of great morphological variability of their spores (Lom and Dyková 1992). However, Molnár et al. (2002), based on SSU rDNA analysis, suggested that $M$. pseudodispar is a valid species. This work also indicated that muscle-dwelling parasites cluster according to fish host species. Forró and Eszterbauer (2016) confirmed this and defined five different clades of M. pseudodispar correlating with fish host species.
The SSU rDNA sequence differences among these clades suggested cryptic species status of M. pseudodispar. Cryptic species phenomenon was also reported for other Myxobolus spp. (e.g., Rocha et al. 2019) and for other myxozoan genera e.g., Chloromyxum Mingazzini, 1890; Sphaerospora Thélohan, 1892; Zschokkela Auerbach, 1910 (see Bartošová and Fiala 2011, Holzer et al. 2013). Moreover, the study of Molnár et al. (2002) indicated that morphologically similar species of Myxobolus from different fishes seem to be different species. In contrast, Guo et al. (2018) suggested that SSU rDNA difference as low as $2.4 \%$ does not necessarily define conspecificity.

In the present study, we aimed to analyse data from a large-scale screening of freshwater fishes to resolve the cryptic species status of $M$. pseudodispar. We assess the host specificity of each $M$. pseudodispar clade and trace the myxospore morphology of $M$. pseudodispar and related species on the evolutionary tree.

\section{MATERIALS AND METHODS}

\section{Sample collection and light microscopy}

During our large-scale research on the biodiversity of myxozoan parasites of freshwater fish in Europe, overall, 452 fish (36 species from different fish orders) were collected in ponds, dams and rivers in the Czech Republic (408) and in the Danube River (44) in Bulgaria during the years 2016-2018. Host species numbers are summarised in Supplementary Table 1.

Fish from the Czech Republic were parasitologically examined using light microscopy (Olympus BX51 microscope) at $400 \times$ magnification to detect the presence of spores, plasmodia or other development stages of Myxozoa in gills, kidney and gall bladder. Other host tissues were not included in the examination, and therefore myxosporean plasmodia in muscles or skin could not be formed. Digital photos of fresh spores were taken at $1000 \times$ magnification using an Olympus DP70 camera. Spores were measured from digital images using ImageJ 1-48q (Wayne Rasband, http://imagej.nih.gov/ij). Gills, kidneys and gall bladders of fish from Bulgaria were fixed only for molecular processing.

\section{DNA isolation, PCR, cloning and sequencing}

All obtained fish tissue samples were kept in $400 \mu$ l of TNES urea buffer $(10 \mathrm{mM}$ Tris- $\mathrm{HCl}$ with $\mathrm{pH} 8 ; 125 \mathrm{mM} \mathrm{NaCl} ; 10 \mathrm{mM}$ EDTA; $0.5 \%$ SDS and $4 \mathrm{M}$ urea). Genomic DNA extraction was performed by standard phenol-chloroform extraction method with four-hour digestion with proteinase $\mathrm{K}$ (50 $\mu \mathrm{g} \mathrm{ml-1} 180$; Serva, Heidelberg, Germany) at $55^{\circ} \mathrm{C}$ and final elution in $100 \mu \mathrm{l}$ of DNAse-free water (Holzer et al. 2004).

We screened all obtained DNA samples for myxozoan infection using nested PCR by general myxozoan primer combination sets for partial SSU rDNA: 18e+18g (Hillis and Dixon 1991) in the first run; MyxGP2 F (Kent et al. 1998) + Act1R (Hallett and Diamant 2001) in the second run. The PCR cycling parameters were set up for first run: denaturation $95^{\circ} \mathrm{C}$ for three min, followed by 35 cycles of three steps: $95^{\circ} \mathrm{C}$ for one min, $62^{\circ} \mathrm{C}$ for one $\min , 72^{\circ} \mathrm{C}$ for two min, and after cycles a final extension $72{ }^{\circ} \mathrm{C}$ for ten min; second run: denaturation $95^{\circ} \mathrm{C}$ for three min, followed by 35 cycles of three steps: $95^{\circ} \mathrm{C}$ for $40 \mathrm{~s}, 56^{\circ} \mathrm{C}$ for 


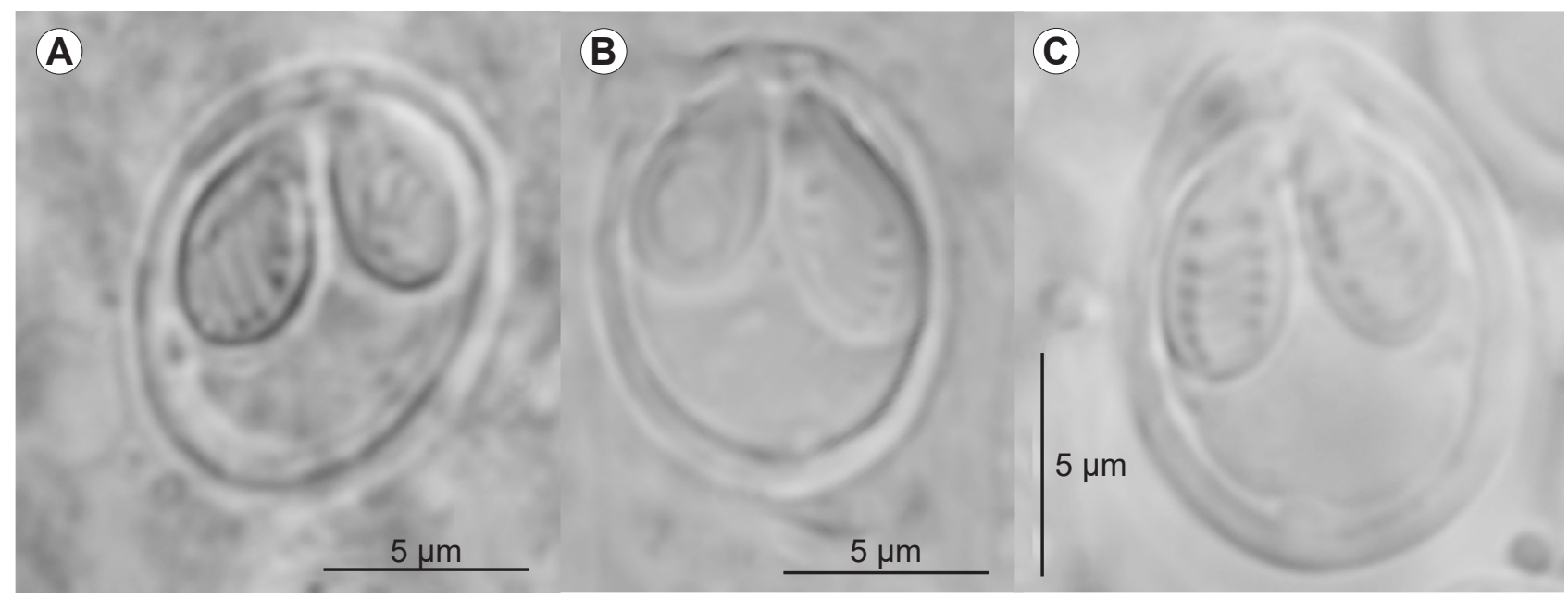

Fig. 1 Myxobolid spores obtained from the kidneys of different fish hosts. A - spore of Myxobolus sp. from Rutilus rutilus (Linnaeus) from Rájský pond, CZ; B - spore of Myxobolus sp. from Phoxinus phoxinus (Linnaeus) from Hostačovka brook, CZ; C - spore of Myxobolus sp. from Gobio gobio (Linnaeus) from Hostačovka brook, CZ.

Table 1. List of primers used for PCR screening including sequence of primers.

\begin{tabular}{|c|c|c|c|}
\hline Primer name & Sequence $\left(5^{\prime} \rightarrow 3^{\prime}\right)$ & $\begin{array}{l}\text { Annealing tem- } \\
\text { perature, }{ }^{\circ} \mathrm{C}\end{array}$ & References \\
\hline $18 \mathrm{e}$ & TGGTTGATCCTGCCAGT & \multirow[b]{2}{*}{64} & \multirow[b]{2}{*}{ Hillis and Dixon (1991) } \\
\hline $18 \mathrm{~g}$ & GGTAGTAGCGACGGGCGGTGTG & & \\
\hline MyxGP2F & WTGGATAACCGTGGGAAA & \multirow{2}{*}{58} & Kent et al. (1998) \\
\hline Act1R & AATTTCACCTCTCGCTGCCA & & Hallett and Diamant (2001) \\
\hline CobF424 & GGWTAYGTWYTWCCWTGRGGWCARAT & \multirow{2}{*}{50} & \multirow{2}{*}{ Boore and Brown (2000) } \\
\hline CobR876 & GCRTAWGCRAAWARRAARTAYCAYTCWGG & & \\
\hline
\end{tabular}

$50 \mathrm{~s}, 72^{\circ} \mathrm{C}$ for one min $40 \mathrm{~s}$ with a final incubation $72^{\circ} \mathrm{C}$ for ten min (details in Table 1).

Determination of the host species was verified by PCR and sequencing if the host identification was doubtful. We used CobF424 + CobR876 primers (Boore and Brown 2000) for amplification of partial mitochondrial cytochrome $b$ gene. The PCR cycling parameters were set up as follows: denaturation $95^{\circ} \mathrm{C}$ for three min, followed by 30 cycles of three steps: $95^{\circ} \mathrm{C}$ for one $\min , 50^{\circ} \mathrm{C}$ for one $\min , 72^{\circ} \mathrm{C}$ for one min with a final incubation $72^{\circ} \mathrm{C}$ for five min.

PCRs of the partial SSU rDNA of the parasite and cytochrome $b$ gene of the host were performed using an AmpOne HS-Taq premix (GeneAll Biotechnology Co., Ltd., Seoul, South Korea) with $10 \mu \mathrm{l}$ of AmpOne HS-Taq premix, $0.5 \mu \mathrm{l}$ of each primer ( $25 \mathrm{pmol}), 8.5 \mu \mathrm{l}$ of water and $0.5 \mu \mathrm{l}$ of extracted DNA (100 $300 \mathrm{ng} / \mu \mathrm{l})$. Obtained PCR products were purified by Gel/PCR DNA Fragments Extraction Kit (Geneaid Biotech Ltd., New Taipei, Taiwan) and sequenced directly by Sanger sequencing (Seqme, Dobřriš, Czech Republic).

PCR products were cloned if the direct sequencing revealed myxozoan coinfections. PCR fragments were cloned into the pDrive vector using a PCR Cloning Kit (Qiagen, Hilden, Germany) and then transformed into competent Escherichia coli cells (Life Technologies, Prague, Czech Republic). Cloned DNA plasmids were extracted and purified by the High Pure Plasmid Isolation Kit (Roche Applied Science, Penzberg, Germany) and three colonies of each plasmid were sequenced by Sanger sequencing (Seqme).

\section{Alignments and phylogenetic analyses}

Two alignments were constructed to reveal phylogenetic relationships of myxobolid SSU rDNA sequences. The first alignment composed of 117 myxosporean partial SSU rDNA, from which 81 sequences were newly obtained in this study and 36 sequences were retrieved from GenBank. The second alignment consisted of the selected sequences representing the groups of very closely related sequences with identical or almost identical sequences. Sequences in both datasets were aligned in MAFFT v7.017 (Katoh et al. 2005) using E-INS-i multiple alignment method implemented in Geneious v11.0.3 (Kearse et al. 2012). The alignments were manually edited and ambiguously aligned regions were removed.

Phylogenetic analysis was done by Bayesian inference (BI) and maximum likelihood (ML) methods. ML analysis was performed with RAxML v7.2.8 (Stamatakis 2006) with a GTR + Г model selected by jModelTest2 (Posada 2008). Bootstrap supports were calculated from 1,000 replications. BI was performed in MrBayes v3.0 (Ronquist and Huelsenbeck 2003) with the GTR $+\Gamma$ model of evolution. MrBayes was run to estimate posterior probabilities over one million generations via two independent runs of four simultaneous Markov Chain Monte Carlo (MCMC) algorithms with every 100th tree saved. Species-specific divergences were identified from proportional distances (in \%) which were calculated in program Geneious based on the SSU rDNA dataset of all sequences under study. 


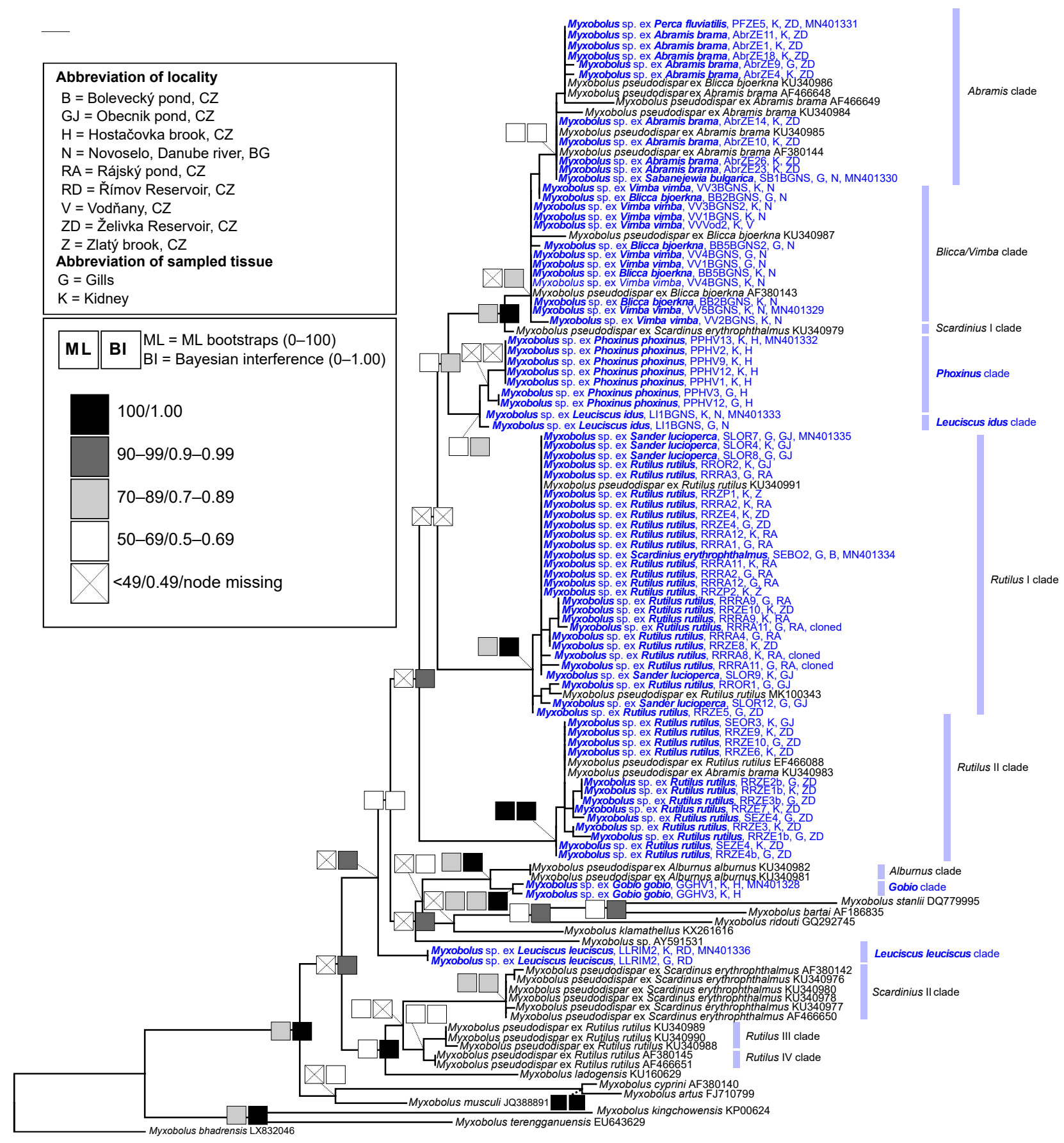

Fig. 2. The phylogenetic tree based on SSU rDNA including all sequences of the Myxobolus pseudodispar Gorbunova, 1936 group and closely related Myxobolus spp. with highlighted individual clades. Myxobolus bhadrensis Seenappa et Manohar, 1981 was used as outgroup. Newly identified sequences are in blue and bold. Maximum likelihood/Bayesian inference nodal supports are shown at every node by colour square according to the appropriate scale shown in the legend.

\section{Topology test}

We used TreeGraph v2.0.47-206 beta (Stöver and Müller 2010) to generate constrained alternate tree topology from the phylogenetic analysis. Designed alternate topology in Newick format was specified in the assumption block of the PAUP* program (Swofford 2001). The dataset with selected ML parameters was executed in PAUP* to generate likelihood scores of the best topology and the constrained tree. Resulted per-site log likelihood scores were analysed for significant differences in CONSEL v6.1 (Shimodaira and Hasegawa 2001), using three likelihood-based tests: approximately unbiased (AU), Kishino-Hasegawa (KH), and Shimodaira-Hasegawa (SH).

\section{RESULTS}

\section{Morphology of Myxobolus pseudodispar}

Myxozoan spores corresponding to the morphological diagnosis of Myxobolus pseudodispar were observed microscopically in fresh tissue preparations of four cypriniform fish: Abramis brama, Gobio gobio (Linnaeus), 

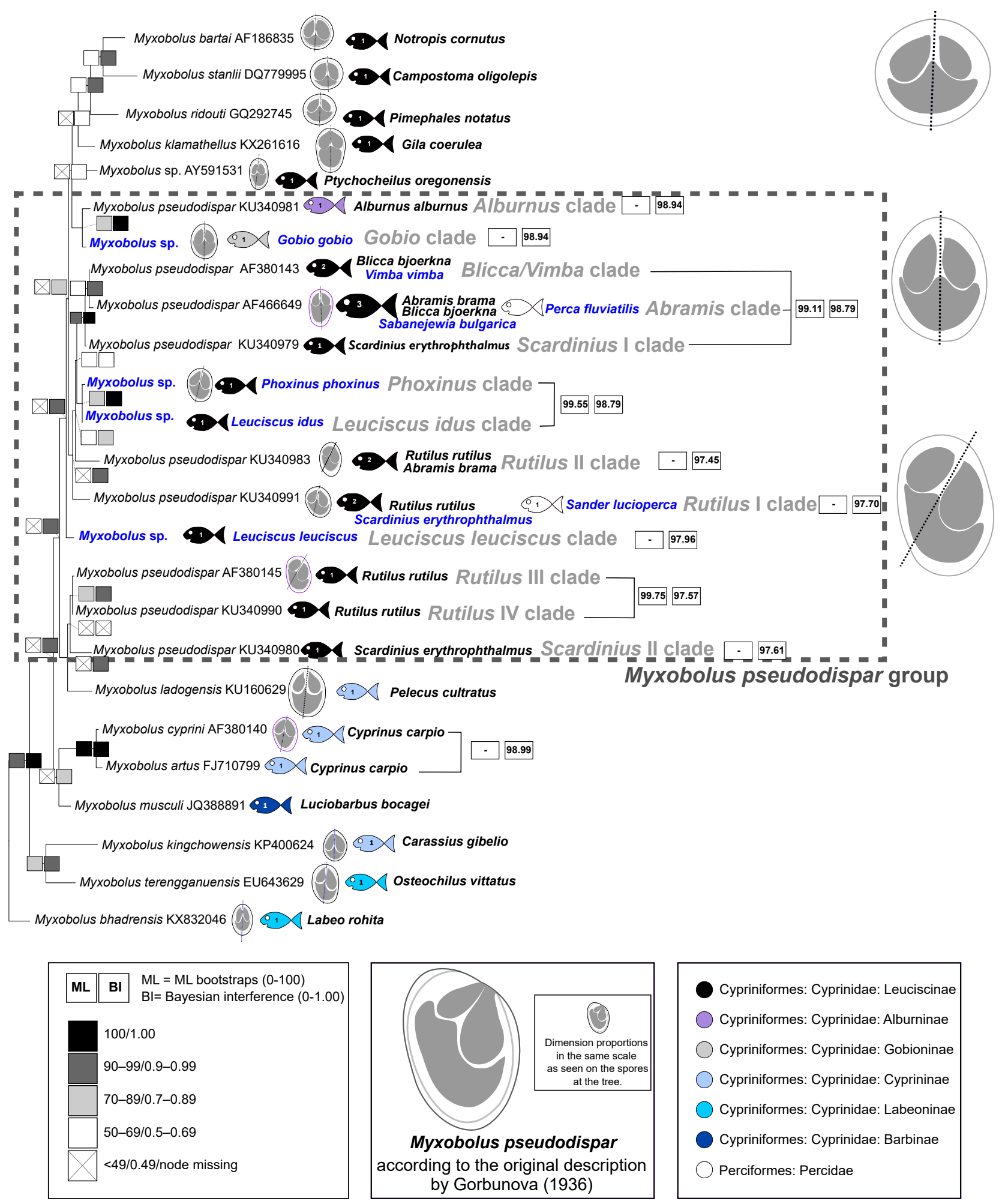

Fig. 3. The phylogenetic tree based on the restricted alignment, in which a representative sequence of each individual clade was included. Each taxon is provided with fish host species the names and comparison of the morphology of myxozoan spores (if available) schematically drawn in the same scale including spore of original description of Myxobolus pseudodispar Gorbunova, 1936 (morphometric data are not available for Leuciscus and Blicca/Vimba clades). Myxobolus bhadrensis Seenappa et Manohar, 1981 was used as outgroup. Newly identified clades and host species are in blue and bold. Maximum likelihood/Bayesian inference nodal supports are shown at every node by colour square according to the appropriate scale shown in the legend. Clamps connect taxa with the sequence similarities higher than $99 \%$ - indicated by the number in the left rectangle next to clade name. The number in the right rectangle shows the sequence similarity of the M. pseudodispar clade (or clade assemblages with similarities higher than 99\%) with the closest related clade. GenBank acc. numbers are given behind the species names. 
Table 2. Prevalence of Myxobolus spp. from the Myxobolus pseudodispar Gorbunova, 1936 group in individual host species screened in the present study including localities and their coordinates.

\begin{tabular}{|c|c|c|c|c|c|c|c|c|}
\hline Host fish & $\begin{array}{l}\text { Nr of } \\
\text { fish }\end{array}$ & Locality & Coordinates & Positive in total & PCR screening & $\begin{array}{c}\text { Prevalence } \\
\text { in total }\end{array}$ & Spores/ Plasmodia observed & Clade \\
\hline \multirow[t]{4}{*}{$\begin{array}{l}\text { Abramis brama } \\
\text { (Linnaeus) }\end{array}$} & 3 & $\begin{array}{l}\text { Obecník pond, } \\
\text { CZ }\end{array}$ & $\begin{array}{l}49^{\circ} 48^{\prime} 46.440 " \mathrm{~N} \\
15^{\circ} 28^{\prime} 28.920^{\prime \prime} \mathrm{E}\end{array}$ & ; $0 \%(0 / 3)$ & gills $0 / 3$; kidney $0 / 3$ & \multirow{4}{*}{$\begin{array}{c}36 \% \\
(13 / 36)\end{array}$} & NA & \multirow{4}{*}{$\begin{array}{c}\text { Abramis } \\
\text { clade }\end{array}$} \\
\hline & 3 & $\begin{array}{l}\text { Římov Reser- } \\
\text { voir, CZ }\end{array}$ & $\begin{array}{l}48^{\circ} 49^{\prime} 58.440 " \mathrm{~N} \\
14^{\circ} 29^{\prime} 0.960^{\prime \prime} \mathrm{E}\end{array}$ & $0 \%(0 / 3)$ & gills $0 / 3$; kidney $0 / 3$ & & NA & \\
\hline & 29 & $\begin{array}{l}\text { Švihov Reser- } \\
\text { voir, CZ }\end{array}$ & $\begin{array}{l}49^{\circ} 40^{\prime} 27.480^{\prime \prime} \mathrm{N} \\
15^{\circ} 9^{\prime} 48.600^{\prime \prime} \mathrm{E}\end{array}$ & ; $45 \%(13 / 29)$ & gills 3/29; kidney1 2/29 & & Spores in kidney & \\
\hline & 1 & $\begin{array}{l}\text { Horusický pond, } \\
\text { CZ }\end{array}$ & $\begin{array}{l}49^{\circ} 9^{\prime} 22.320^{\prime \prime} \mathrm{N} \\
14^{\circ} 40^{\prime} 28.200^{\prime \prime} \mathrm{E}\end{array}$ & $0 \%(0 / 1)$ & gills $0 / 1$ & & NA & \\
\hline \multirow[t]{2}{*}{$\begin{array}{l}\text { Blicca bjoerkna } \\
\text { (Linnaeus) }\end{array}$} & 6 & $\begin{array}{l}\text { Švihov Reser- } \\
\text { voir, CZ }\end{array}$ & $\begin{array}{l}49^{\circ} 40^{\prime} 27.480^{\prime \prime} \mathrm{N} \\
15^{\circ} 9^{\prime} 48.600^{\prime \prime} \mathrm{E}\end{array}$ & ; $0 \%(0 / 6)$ & gills $0 / 6$; kidney $0 / 6$ & \multirow{2}{*}{$27 \%(3 / 11)$} & NA & \multirow{2}{*}{$\begin{array}{l}\text { Blicca/Vim- } \\
\text { ba clade }\end{array}$} \\
\hline & 5 & $\begin{array}{l}\text { Novo Selo, Dan- } \\
\text { ube River, BG }\end{array}$ & $\begin{array}{l}-44^{\circ} 09^{\prime} 46^{\prime \prime N} \text {; } \\
22^{\circ} 47^{\prime} 17^{\prime \prime} \mathrm{E}\end{array}$ & $60 \%(3 / 5)$ & gills $3 / 5$; kidney $3 / 5$ & & NA & \\
\hline \multirow[t]{4}{*}{$\begin{array}{l}\text { Gobio gobio } \\
\text { (Linnaeus) }\end{array}$} & 6 & $\begin{array}{l}\text { Hostačovka } \\
\text { brook, CZ }\end{array}$ & $\begin{array}{l}49^{\circ} 48^{\prime} 56.707 " \mathrm{~N} \\
15^{\circ} 31^{\prime} 48.786^{\prime \prime} \mathrm{E}\end{array}$ & $33 \%(2 / 6)$ & gills $0 / 6$; kidney $2 / 6$ & \multirow{4}{*}{$17 \%(2 / 12)$} & Spores in kidney & \multirow{4}{*}{$\begin{array}{l}\text { Gobio } \\
\text { clade }\end{array}$} \\
\hline & 3 & $\begin{array}{l}\text { Švihov Reser- } \\
\text { voir, CZ }\end{array}$ & $\begin{array}{l}49^{\circ} 40^{\prime} 27.480 " \mathrm{~N} \\
15^{\circ} 9^{\prime} 48.600^{\prime \prime} \mathrm{E}\end{array}$ & $; 0 \%(0 / 3)$ & gills $0 / 3$; kidney $0 / 3$ & & NA & \\
\hline & 2 & $\begin{array}{l}\text { Klíčava Reser- } \\
\text { voir, CZ }\end{array}$ & $\begin{array}{l}50^{\circ} 4^{\prime} 11.640 " \mathrm{~N} \\
13^{\circ} 55^{\prime} 48.000^{\prime \prime} \mathrm{E}\end{array}$ & $0 \%(0 / 2)$ & gills $0 / 2$; kidney $0 / 2$ & & NA & \\
\hline & 1 & Jihlava River, & $\begin{array}{l}49^{\circ} 12^{\prime} 45.714^{\prime \prime N} \\
15^{\circ} 56^{\prime} 44.319^{\prime \prime} \mathrm{E}\end{array}$ & $; 0 \%(0 / 1)$ & gills $0 / 1$; kidney $0 / 1$ & & NA & \\
\hline \multirow[t]{5}{*}{$\begin{array}{l}\text { Leuciscus idus } \\
\text { (Linnaeus) }\end{array}$} & 10 & $\begin{array}{l}\text { Hostačov pond, } \\
\text { CZ }\end{array}$ & $\begin{array}{l}49^{\circ} 50^{\prime} 51.720^{\prime \prime} \mathrm{N} \\
15^{\circ} 29^{\prime} 44.160^{\prime \prime} \mathrm{E}\end{array}$ & $0 \%(0 / 10)$ & gills $0 / 9$; kidney $0 / 10$ & \multirow{5}{*}{$6 \%(1 / 16)$} & NA & \multirow{5}{*}{$\begin{array}{l}\text { Leuciscus } \\
\text { idus clade }\end{array}$} \\
\hline & 2 & $\begin{array}{l}\text { Švihov Reser- } \\
\text { voir, CZ }\end{array}$ & $\begin{array}{l}49^{\circ} 40^{\prime} 27.480 " \mathrm{~N} \\
15^{\circ} 9^{\prime} 48.600 " \mathrm{E}\end{array}$ & $0 \%(0 / 2)$ & gills $0 / 2$; kidney $0 / 2$ & & NA & \\
\hline & 1 & $\begin{array}{l}\text { Lužnice River, } \\
\text { CZ }\end{array}$ & $\begin{array}{l}49^{\circ} 3^{\prime} 14.760^{\prime \prime N} \\
14^{\circ} 45^{\prime} 46.800^{\prime \prime} \mathrm{E}\end{array}$ & $0 \%(0 / 1)$ & gills $0 / 1$; kidney $0 / 1$ & & NA & \\
\hline & 1 & $\begin{array}{l}\text { Novo Selo, Dan- } \\
\text { ube River, BG }\end{array}$ & $\begin{array}{l}-44^{\circ} 09^{\prime} 46^{\prime \prime N} \text {; } \\
22^{\circ} 47^{\prime} 17^{\prime \prime} \mathrm{E}\end{array}$ & $100 \%(1 / 1)$ & gills $1 / 1$; kidney $1 / 1$ & & NA & \\
\hline & 1 & $\begin{array}{l}\text { Topolovec, Dan- } \\
\text { ube River, BG }\end{array}$ & $\begin{array}{l}-43^{\circ} 566^{\prime 2} 7.395^{\prime \prime} \mathrm{N} \\
22^{\circ} 50^{\prime} 21.820^{\prime \prime} \mathrm{E}\end{array}$ & $; 0 \%(0 / 1)$ & gills $0 / 1$; kidney $0 / 1$ & & NA & \\
\hline \multirow[t]{2}{*}{$\begin{array}{l}\text { Leuciscus leucis } \\
\text { cus (Linnaeus) }\end{array}$} & -2 & $\begin{array}{l}\text { Jihlava River, } \\
\text { CZ }\end{array}$ & $\begin{array}{l}49^{\circ} 12^{\prime} 45.714 " \mathrm{~N} \\
15^{\circ} 56^{\prime} 44.319^{\prime \prime} \mathrm{E}\end{array}$ & $0 \%(0 / 2)$ & gills $0 / 2$; kidney $0 / 2$ & \multirow[b]{2}{*}{$20 \%(1 / 5)$} & NA & \multirow{2}{*}{$\begin{array}{l}\text { Leuciscus } \\
\text { leuciscus } \\
\text { clade }\end{array}$} \\
\hline & 3 & $\begin{array}{l}\text { Římov Reser- } \\
\text { voir, CZ }\end{array}$ & $\begin{array}{l}48^{\circ} 49^{\prime} 58.440 " \mathrm{~N} \\
14^{\circ} 29^{\prime} 0.960^{\prime \prime} \mathrm{E}\end{array}$ & $33 \%(1 / 3)$ & gills $1 / 3$; kidney $1 / 2$ & & NA & \\
\hline \multirow[t]{8}{*}{$\begin{array}{l}\text { Perca fluviatilis } \\
\text { Linnaeus }\end{array}$} & 3 & $\begin{array}{l}\text { Hostačov pond, } \\
\text { CZ }\end{array}$ & $\begin{array}{l}49^{\circ} 50^{\prime} 51.720 " \mathrm{~N} \\
15^{\circ} 29^{\prime} 44.160^{\prime \prime} \mathrm{E}\end{array}$ & $0 \%(0 / 3)$ & gills $0 / 3$; kidney $0 / 3$ & \multirow{8}{*}{$5 \%(2 / 38)$} & NA & \multirow{8}{*}{$\begin{array}{l}\text { Abramis } \\
\text { clade }\end{array}$} \\
\hline & 10 & Milada Lake, CZ & $\begin{array}{l}50^{\circ} 39^{\prime} 14.040^{\prime \prime} \mathrm{N} \\
13^{\circ} 56^{\prime} 52.440^{\prime \prime}\end{array}$ & $0 \%(0 / 10)$ & gills $0 / 10$; kidney $0 / 10$ & & NA & \\
\hline & 4 & $\begin{array}{l}\text { Obecník pond, } \\
\text { CZ }\end{array}$ & $\begin{array}{l}49^{\circ} 48^{\prime} 46.440 " \mathrm{~N} \\
15^{\circ} 28^{\prime} 28.920^{\prime \prime} \mathrm{E}\end{array}$ & $0 \%(0 / 4)$ & gills $0 / 4$; kidney $0 / 4$ & & NA & \\
\hline & 4 & Rájský pond, CZ & 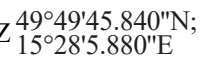 & ; $0 \%(0 / 4)$ & gills $0 / 4$; kidney $0 / 4$ & & NA & \\
\hline & 3 & $\begin{array}{l}\text { Římov Reser- } \\
\text { voir, CZ }\end{array}$ & $\begin{array}{l}48^{\circ} 49^{\prime} 58.440^{\prime \prime} \mathrm{N} \\
14^{\circ} 29^{\prime} 0.960^{\prime \prime} \mathrm{E}\end{array}$ & $0 \%(0 / 3)$ & gills $0 / 3$; kidney $0 / 1$ & & NA & \\
\hline & 7 & $\begin{array}{l}\text { Švihov Reser- } \\
\text { voir, CZ }\end{array}$ & $\begin{array}{l}49^{\circ} 40 ' 27.480 " \mathrm{~N} \\
15^{\circ} 9^{\prime} 48.600^{\prime \prime} \mathrm{E}\end{array}$ & $; 14 \%(1 / 7)$ & gills $0 / 7$; kidney $1 / 7$ & & NA & \\
\hline & 6 & Zlatý brook, $\mathrm{CZ}$ & $\begin{array}{l}49^{\circ} 7^{\prime} 46.188^{\prime \prime N} \\
13^{\circ} 34^{\prime} 43.040^{\prime \prime} \mathrm{E}\end{array}$ & $17 \%(1 / 6)$ & gills $1 / 6$; kidney $1 / 6$ & & Plasmodia in gills & \\
\hline & 1 & $\begin{array}{l}\text { Horusický pond, } \\
\text { CZ }\end{array}$ & $\begin{array}{l}49^{\circ} 9^{\prime} 22.320 " \mathrm{~N} \\
14^{\circ} 40^{\prime} 28.200^{\prime \prime} \mathrm{E}\end{array}$ & $0 \%(0 / 1)$ & gills $0 / 1$ & & NA & \\
\hline \multirow[t]{3}{*}{$\begin{array}{l}\text { Phoxinus phoxi- } \\
\text { nus (Linnaeus) }\end{array}$} & 14 & $\begin{array}{l}\text { Hostačovka } \\
\text { brook, CZ }\end{array}$ & $\begin{array}{l}49^{\circ} 48^{\prime} 56.707 " \mathrm{~N} \\
15^{\circ} 31^{\prime} 48.786^{\prime \prime} \mathrm{E}\end{array}$ & $71 \%(10 / 14)$ & $\begin{array}{l}\text { gills } 4 / 14 ; \text { kidney } 7 / 14 ; \\
\text { muscle }=1 / 1\end{array}$ & \multirow{3}{*}{$\begin{array}{c}65 \% \\
(11 / 17)\end{array}$} & $\begin{array}{l}\text { Spores in kidney and gills; } \\
\text { plasmodia in kidney }\end{array}$ & \multirow{3}{*}{$\begin{array}{l}\text { Phoxinus } \\
\text { clade }\end{array}$} \\
\hline & 2 & Černá River, CZ & $\begin{array}{l}48^{\circ} 43.44528^{\prime} \mathrm{N} \\
14^{\circ} 35.60745^{\prime} \mathrm{E}\end{array}$ & $50 \%(1 / 2)$ & $\begin{array}{l}\text { gills } 0 / 2 ; \text { kidney } 0 / 2 ; \\
\text { skin }=1 / 1\end{array}$ & & Spores on skin & \\
\hline & 1 & $\begin{array}{l}\text { Hostačov pond, } \\
\text { CZ }\end{array}$ & $\begin{array}{l}49^{\circ} 50^{\prime} 51.720 " \mathrm{~N} \\
15^{\circ} 29^{\prime} 44.160^{\prime \prime} \mathrm{E}\end{array}$ & $; 0 \%(0 / 1)$ & gills $0 / 1$; kidney $0 / 1$ & & NA & \\
\hline \multirow[t]{7}{*}{$\begin{array}{l}\text { Rutilus rutilus } \\
\text { (Linnaeus) }\end{array}$} & 15 & $\begin{array}{l}\text { Švihov Reser- } \\
\text { voir, CZ }\end{array}$ & $\begin{array}{l}49^{\circ} 40^{\prime} 27.480 " \mathrm{~N} \\
15^{\circ} 9^{\prime} 48.600^{\prime \prime} \mathrm{E}\end{array}$ & $; 81 \%(13 / 16)$ & $\begin{array}{l}\text { gills 6/16; kidney 6/16 } \\
\text { (Rutilus clade 2); gills } \\
\text { 2/16; kidney 2/16 (Ruti- } \\
\text { lus clade 1) }\end{array}$ & \multirow{4}{*}{$21 \%(9 / 42)$} & $\begin{array}{l}\text { Spores in gills and in kidney; } \\
\text { plasmodia in gills (Rutilus } \\
\text { clade 2); Spores in kidney } \\
\text { (Rutilus clade 1) }\end{array}$ & \multirow{7}{*}{$\begin{array}{l}\text { Rutilus } \\
\text { clade } \\
1 / 2\end{array}$} \\
\hline & 5 & $\begin{array}{l}\text { Hostačovka } \\
\text { brook, CZ }\end{array}$ & $\begin{array}{l}49^{\circ} 48^{\prime} 56.707 " \mathrm{~N} \\
15^{\circ} 31^{\prime} 48.786^{\prime E} \mathrm{E}\end{array}$ & $; 0 \%(0 / 5)$ & gills $0 / 5$; kidney $0 / 5$ & & NA & \\
\hline & 12 & Rájský pond, CZ & 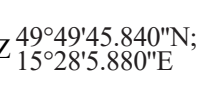 & ; $83 \%(10 / 12)$ & $\begin{array}{l}\text { gills } 7 / 12 \text {; kidney } 5 / 8 \\
\text { (Rutilus clade } 2 \text { ) }\end{array}$ & & $\begin{array}{l}\text { Spores in gills and in kidney; } \\
\text { plasmodia in gills } \\
\text { (Rutilus clade 2) }\end{array}$ & \\
\hline & 3 & $\begin{array}{l}\text { Římov Reser- } \\
\text { voir, CZ }\end{array}$ & $\begin{array}{l}48^{\circ} 49^{\prime} 58.440^{\prime \prime} \mathrm{N} \\
14^{\circ} 29^{\prime} 0.960^{\prime \prime} \mathrm{E}\end{array}$ & $0 \%(0 / 3)$ & gills $0 / 3$; kidney $0 / 3$ & & NA & \\
\hline & 2 & Zlatý brook, $\mathrm{CZ}$ & $\begin{array}{l}49^{\circ} 7^{\prime} 46.188^{\prime \prime N} \\
13^{\circ} 34^{\prime} 43.040^{\prime \prime} \mathrm{E}\end{array}$ & $100 \%(2 / 2)$ & $\begin{array}{l}\text { gills } 0 / 2 ; \text { kidney } 2 / 2 \\
\text { (Rutilus clade 1) }\end{array}$ & \multirow{3}{*}{$45(19 / 42)$} & $\begin{array}{l}\text { Spores in kidney } \\
\text { (Rutilus clade 1) }\end{array}$ & \\
\hline & 2 & $\begin{array}{l}\text { Obecník pond, } \\
\text { CZ }\end{array}$ & $\begin{array}{l}49^{\circ} 48^{\prime} 46.440 " \mathrm{~N} \\
15^{\circ} 28^{\prime} 28.920^{\prime \prime} \mathrm{E}\end{array}$ & ; $100 \%(3 / 3)$ & $\begin{array}{l}\text { gills } 0 / 3 \text {; kidney } 1 / 3 \\
\text { (Rutilus clade } 2) \text {; gills } \\
1 / 3 \text {; kidney } 1 / 3 \text { (Rutilus } \\
\text { clade } 1)\end{array}$ & & NA & \\
\hline & 1 & $\begin{array}{l}\text { Horusický pond, } \\
\text { CZ }\end{array}$ & $\begin{array}{l}49^{\circ} 9^{\prime} 22.320^{\prime \prime N} \\
14^{\circ} 40^{\prime} 28.200^{\prime \prime} \mathrm{E}\end{array}$ & $0 \%(0 / 1)$ & gills $0 / 1$ & & NA & \\
\hline
\end{tabular}




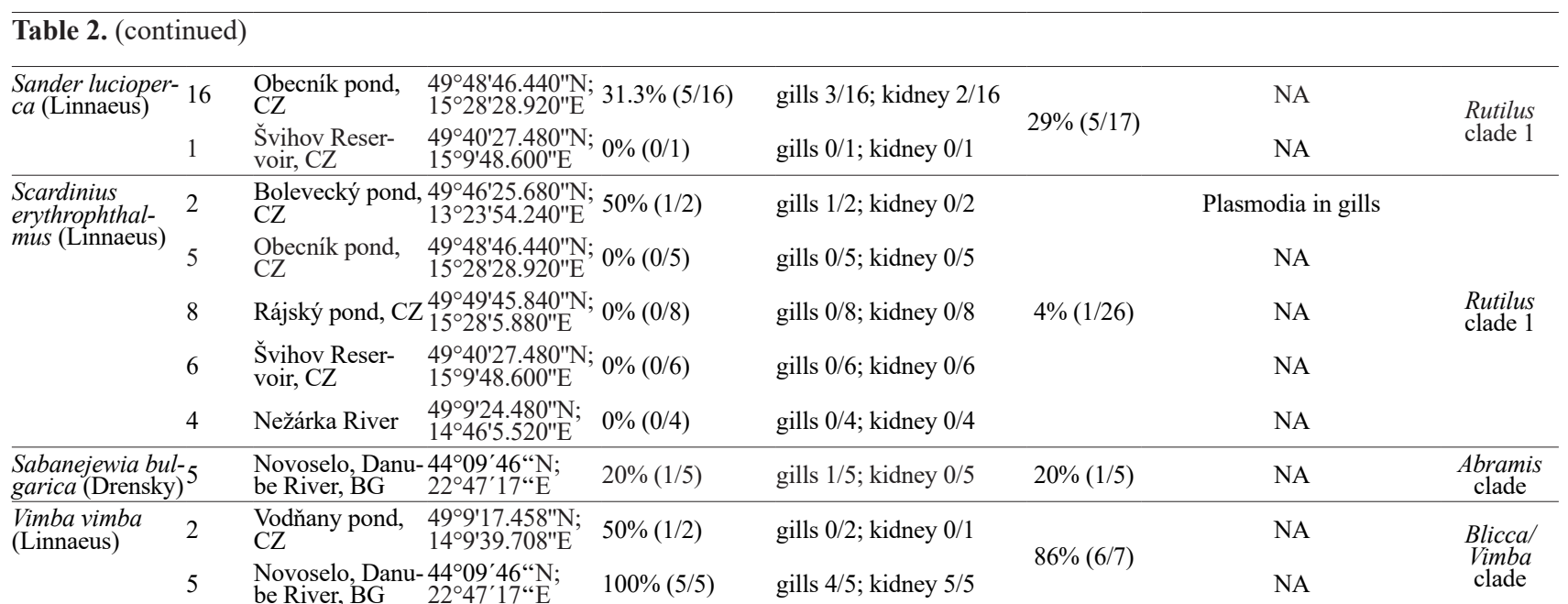

Phoxinus phoxinus (Linnaeus) and Rutilus rutilus (Fig. 1). Plasmodia of the Myxobolus origin were observed in gills of $A$. brama, in kidney and gills of $R$. rutilus and in kidney of $P$. phoxinus and in gills of Scardinius erythrophthalmus (see Table 2).

Spore dimensions mean with standard deviation were measured for myxobolid spores from (i) $R$. rutilus from Švihov Reservoir (RRZE1b, $\mathrm{n}=9$ ) with length $10.34 \mu \mathrm{m}( \pm$ $0.61 \mathrm{SD})$, width $6.95( \pm 0.32 \mu \mathrm{m})$, polar capsules length 4.91 $\mu \mathrm{m}( \pm 0.67 \mathrm{SD})$ and width $3.12 \mu \mathrm{m}( \pm 0.86 \mathrm{SD})$; (ii) $R$. rutilus from Rájský pond (RRRA3 + RRRA9, n=5) with length $10.06 \mu \mathrm{m}( \pm 0.62 \mathrm{SD})$, width $7.59 \mu \mathrm{m}( \pm 0.96 \mathrm{SD})$ and polar capsules length $4.77 \mu \mathrm{m}( \pm 0.67 \mathrm{SD})$ and width $2.89 \mu \mathrm{m}( \pm$ $0.31 \mathrm{SD}$ ); (iii) P. phoxinus from Hostačovka brook (PPHV1, $\mathrm{n}=5)$ with length $10.85 \mu \mathrm{m}( \pm 0.92 \mathrm{SD})$, width $8.93 \mu \mathrm{m}( \pm$ $0.14 \mathrm{SD})$ and polar capsules length $5.14 \mu \mathrm{m}( \pm 1.1 \mathrm{SD})$ and width $3.09 \mu \mathrm{m}$ ( $\pm 0.38 \mathrm{SD})$; iv) G. gobio from Hostačovka brook (GGHV3, n=7) with length $11.7 \mu \mathrm{m}( \pm 0.2 \mathrm{SD})$, width $8.3 \mu \mathrm{m}( \pm 0.8 \mathrm{SD})$ and polar capsules length $5.5 \mu \mathrm{m}( \pm 0.2$ SD) and width $2.9 \mu \mathrm{m}$ ( $\pm 0.3 \mathrm{SD})$. (see Table 3 for spore dimension details of all myxobolids included in the phylogenetic analysis).

\section{Host species spectrum and coinfections}

We screened using PCR 452 fish from several localities in the Czech Republic and two localities in Bulgaria and subsequently sequenced positive PCR products (Supplementary file 1). The highest prevalence of $M$. pseudodispar was detected in vimba bream, Vimba vimba (Linnaeus) $(86 \% ; 6 / 7)$, common roach, R. rutilus $(67 \% ; 28 / 42)$ and common minnow, $P$. phoxinus $(65 \%$; 11/17). Lower prevalence has been found in other cyprinids: freshwater bream A. brama $(36 \% ; 13 / 36)$ white bream, Blicca bjoerkna $(27 \%$; 3/11) gudgeon, G. gobio $(17 \% ; 2 / 12)$ ide, Leuciscus idus (Linnaeus) $(6 \% ; 1 / 16)$ common dace, Leuciscus leuciscus (Linnaeus) $(20 \% ; 1 / 5)$, Sabanejewia bulgarica (Drensky) (20\%; 1/5), and common rudd, S. erythrophthalmus $(3.8 \%$; 1/26). Myxozoans were detected in two perciform fish: European perch, Perca fluviatilis Linnaeus $(5 \%$; $2 / 38)$ and pikeperch, Sander lucioperca (Linnaeus) (29\%; 5/17) (Table 2 ). One sample of the gall bladder from $P$. phoxinus was PCR positive for $M$. pseudodispar, which may represent detection of pre-sporogonic stages of this parasite since we did not observe any spores and plasmodia in the bile. Myxobolus diversicapsularis Slukhai in Shulman, 1966; M. elegans Kashkovski in Shulman, 1966; M. parviformis Kallert, Eszterbauer, Erseus, El-Matbouli et Haas, 2005; Myxidium spp.; Henneguya sp. and Chloromyxum sp. were morphologically and molecularly identified in coinfections with M. pseudodispar.

\section{Phylogenetic analyses}

The phylogenetic tree based on SSU rDNA revealed that all newly obtained sequences clustered in close relation to M. pseudodispar sequences from GenBank (Fig. 2). They clearly grouped according to fish host species preferences forming 13 well-recognised clades. Part of the newly obtained sequences are identical or almost identical to already known sequences that clustered in clades named according to their predominant hosts: Abramis, Blicca/Vimba, Rutilus I and Rutilus II. Four new clades were explored by our new sequence data: Gobio, L. leuciscus, L. idus and Phoxinus. None of our newly obtained sequences clustered to five already identified M. pseudodispar sequences forming clades Alburnus, Rutilus III and IV, Scardinius I and II (Fig. 2). Sequence similarities among most of the clades in the M. pseudodispar group ranged from $90.1 \%$ to $99.8 \%$, whereas only three clades exceeded $99 \%$ of sequence similarity between their members (Fig. 3).

Our analysis suggested that not all phylogenetic clades of M. pseudodispar shared a common ancestor. The paraphyletic character of M. pseudodispar group is caused by the clustering of Myxobolus bartai Salim et Desser, 2000 (AF186835), M. klamathellus Atkinson et Banner, 2017 (KX261616), M. ladogensis Rumyantsev et Shulman, 1997 (KU160629), M. ridouti Easy et Cone, 2009 (GQ292745), M. stanlii Iwanowicz et Iwanowicz, 2013 (DQ779995) and Myxobolus sp. (AY591531) within this group. Particularly, Alburnus and Gobio clades are sister related to the above-mentioned species of Myxobolus except for $M$. ladogensis, which is a sister taxon to Rutilus III, Rutilus IV and Scardinius I clades. We performed statistical tests to assess the possible monophyletic status of $M$. pseudodispar sequences. The best topology resulted from the 
Table 3. Details of all species of Myxobolus Bütschli, 1882 included in the phylogenetic analyses names of hosts, fish organs or tissues, GenBank accession numbers for parasite taxa and spore dimensions (length $\times$ width).

\begin{tabular}{|c|c|c|c|c|c|}
\hline Myxozoan species & Host & Fish organ or tissue & $\begin{array}{l}\text { GenBank Acc. } \\
\text { No. }\end{array}$ & $\begin{array}{l}\text { Spore dimensions (length } \times \\
\text { width) } \pm \text { standard deviation }\end{array}$ & Reference \\
\hline M. artus Akhmerov, 1960 & Cyprinus carpio & Skeletal muscle & FJ710799 & NA & Zhang et al. (2010) \\
\hline M. bartai Salim et Desser, 2000 & Notropis cornutus & $\begin{array}{l}\text { Body wall muscu- } \\
\text { lature }\end{array}$ & AF186835 & $\begin{array}{l}11.0(10.3-11.4) \times 10.8 \\
(10.0-11.3)\end{array}$ & $\begin{array}{l}\text { Salim and Desser } \\
(2000)\end{array}$ \\
\hline $\begin{array}{l}\text { M. bhadrensis Seenappa et Mano- } \\
\text { har, } 1981\end{array}$ & Labeo rohita & Kidney & KX832046 & $\begin{array}{l}10.0 \pm 0.41(9.2-10.4) \times 6.6 \pm \\
0.37(6.0-7.2)\end{array}$ & Zhang et al. (2018) \\
\hline M. cyprini Doflein, 1898 & Cyprinus carpio & Muscle & AF380140 & NA & Molnár et al. (2002) \\
\hline $\begin{array}{l}\text { M. kingchowensis Chen et Ma, } \\
1998\end{array}$ & Carassius gibelio & Muscle & KP400624 & $\begin{array}{l}11.21 \pm 0.64(9.63-12.20) \times \\
8.43 \pm 0.32(7.83-9.14)\end{array}$ & Zhang et al. (2018) \\
\hline $\begin{array}{l}\text { M. klamathellus Atkinson et } \\
\text { Banner, } 2017\end{array}$ & Gila coerulea & $\begin{array}{l}\text { Subcutaneous and } \\
\text { kidney }\end{array}$ & KX261616 & $\begin{array}{l}14.3 \pm 0.4(13-15) \times 9.7 \pm 0.4 \\
(9-10)\end{array}$ & $\begin{array}{l}\text { Atkinson and Banner } \\
(2017)\end{array}$ \\
\hline $\begin{array}{l}\text { M. ladogensis Rumyantsev et } \\
\text { Shulman, } 1997\end{array}$ & - & Muscle & KU160629 & NA & $\begin{array}{l}\text { Liu et al. (2015), } \\
\text { unpublished }\end{array}$ \\
\hline M. musculi Keisselitz, 1908 & Luciobarbus bocagei & Muscle & JQ388891 & NA & Molnár et al. (2002) \\
\hline M. pseudodispar Gorbunova, 1936 & Abramis brama & $\begin{array}{l}\text { Muscle, kidney, } \\
\text { gills, skin }\end{array}$ & $\begin{array}{l}\text { AF380144 } \\
\text { AF466648-9 } \\
\text { KU340984-6 }\end{array}$ & NA & $\begin{array}{l}\text { present study, Molnár } \\
\text { et al. (2002) }\end{array}$ \\
\hline M. pseudodispar & Alburnus alburnus & Muscle & KU340981 & NA & $\begin{array}{l}\text { Forró and Eszterbauer } \\
(2016)\end{array}$ \\
\hline M. pseudodispar & $\begin{array}{l}\text { Rutilus rutilus, Abras- } \\
\text { mis brama }\end{array}$ & Gills, kidney & $\begin{array}{l}\text { EF466088 } \\
\text { KU340983 }\end{array}$ & $\begin{array}{l}10.34 \pm 0.61(9.4-11.1) \times 6.95 \\
\pm 0.32(6.4-7.3)\end{array}$ & 5 present study \\
\hline M. pseudodispar & $\begin{array}{l}\text { Rutilus rutilus, Sander } \\
\text { lucioperca, Scardinius } \\
\text { erythrophthalmus }\end{array}$ & Gills, kidney & $\begin{array}{l}\text { KU340991 } \\
\text { MK100343 }\end{array}$ & $\begin{array}{l}10.06 \pm 0.62(9.3-10.8) \times 7.59 \\
\pm 0.96(6.3-8.6)\end{array}$ & 9 present study \\
\hline M. pseudodispar & Rutilus rutilus & Muscle & $\begin{array}{l}\text { AF380145 } \\
\text { AF466651 }\end{array}$ & NA & Molnár et al. (2002) \\
\hline M. pseudodispar & Rutilus rutilus & Muscle & KU340988-90 & NA & $\begin{array}{l}\text { Forró and Eszterbauer } \\
\text { (2016) }\end{array}$ \\
\hline M. pseudodispar & $\begin{array}{l}\text { Scardinius erythro- } \\
\text { phthalmus }\end{array}$ & Muscle & KU340979 & NA & $\begin{array}{l}\text { Forró and Eszterbauer } \\
\text { (2016) }\end{array}$ \\
\hline M. pseudodispar & $\begin{array}{l}\text { Scardinius erythro- } \\
\text { phthalmus }\end{array}$ & Muscle & $\begin{array}{l}\text { KU340976-8 } \\
\text { KU340980 } \\
\text { AF466650 } \\
\text { AF380142 }\end{array}$ & NA & $\begin{array}{l}\text { Forró and Eszterbauer } \\
\text { (2016) }\end{array}$ \\
\hline M. ridouti Easy et Cone, 2009 & Pimephales notatus & Muscle & GQ292745 & $\begin{array}{l}9.9 \pm 0.3(9.5-10.5) \times 10.1 \pm \\
0.4(9.4-10.9)\end{array}$ & Easy and Cone (2009) \\
\hline $\begin{array}{l}\text { M. stanlii Iwanowicz et Iwa- } \\
\text { nowicz, } 2013\end{array}$ & Campostoma oligolepis & Suscle & DQ779995 & $\begin{array}{l}10.0 \pm 0.7(7.5-11.0) \times 8.8 \pm \\
1.5(6.3-11.3)\end{array}$ & $\begin{array}{l}\text { Iwanowicz et al. } \\
\text { (2013) }\end{array}$ \\
\hline $\begin{array}{l}\text { M. terengganuensis Székely, Sha- } \\
\text { harom-Harrison, Cech, Ostoros et } \\
\text { Molnár, } 2009\end{array}$ & Osteochilus vittatus & Muscle & EU643629 & $\begin{array}{l}12.7 \pm 0.51(12-13.4) \times 7.4 \pm \\
0.53(6.7-8.3)\end{array}$ & Székely et al. (2009) \\
\hline Myxobolus sp. & Gobio gobio & Kidney & MN401328 & $\begin{array}{l}11.75 \pm 0.24(11.5-12.1) \times \\
8.28 \pm 0.79(7.3-9.5)\end{array}$ & present study \\
\hline Myxobolus sp. & Leuciscus idus & Gills, kidney & MN401333 & NA & present study \\
\hline Myxobolus sp. & Leuciscus leuciscus & Gills, kidney & MN401336 & NA & present study \\
\hline Myxobolus sp. & Perca fluviatilis & Gills & MN401331 & NA & present study \\
\hline Myxobolus sp. & Phoxinus phoxinus & $\begin{array}{l}\text { Gills, kidney, skin, } \\
\text { bile, muscle }\end{array}$ & MN401332 & $\begin{array}{l}10.85 \pm 0.92(9.2-11.86) \times \\
8.93 \pm 0.14(8.8-9.2)\end{array}$ & present study \\
\hline Myxobolus sp. & $\begin{array}{l}\text { Ptychocheilus orego- } \\
\text { nensis }\end{array}$ & Muscle & AY591531 & NA & Kent et al. (2004) \\
\hline Myxobolus sp. & Sabanejewia bulgarica & Gills & MN401330 & NA & present study \\
\hline Myxobolus sp. & Sander lucioperca & Gills, kidney & MN401335 & NA & present study \\
\hline Myxobolus sp. & $\begin{array}{l}\text { Scardinius erythro- } \\
\text { phthalmus }\end{array}$ & Gills & MN401334 & NA & present study \\
\hline Myxobolus sp. & Vimba vimba & Gills, kidney & MN401329 & NA & present study \\
\hline
\end{tabular}

ML analysis with paraphyletic character tested against the constrained topology with monophyletic M. pseudodispar sequences. All statistical tests (AU, SH and $\mathrm{KH}$ ) rejected the monophyly of $M$. pseudodispar at the significance level 0.05 (Supplementary Table 2).

Although M. pseudodispar SSU rDNA sequence clades reflect host species affinity, there are few exceptions to this trend. Myxobolus pseudodispar from R. rutilus (Rutilus I clade) was also identified in five specimens of $S$. lucioper$c a$ and in one individual of S. erythrophthalmus. This clade showed high nodal support in both ML and BI analyses (87/1.0). The Rutilus II clade with ML/BI nodal support
(100/1.0) includes the sequence from one specimen of $A$. brama (KU340983). The Abramis clade with predominant sequences from $A$. brama also includes sequences from $B$. bjoerkna, S. bulgarica and the perciform fish $P$. fluviatilis (Fig. 3).

No phylogenetic trend according to the site of infection was observed except the Phoxinus clade that showed a clear pattern of kidney and gills associated sequence clusters. Similarly, there was no tendency of clustering of $M$. pseudodispar sequences from the same geographic region.

In order to assess the influence of the taxon sampling on phylogenetic distribution, nodal support and cryptic status of 
Myxobolus pseudodispar, we created a less comprehensive dataset for the phylogenetic analysis, in which a representative sequence of each $M$. pseudodispar clade was included (Fig. 3). The resulting tree was additionally supplied by information about the systematic classification of the hosts and the comparison of the morphology of myxozoan spores (if available). This restricted analysis suggested almost the same topology as the comprehensive phylogenetic analysis of all obtained sequences. The only difference is the switch of the branching of the Rutilus I and Rutilus II clades. Nodal support remained generally low, however, several nodes were better supported in the restricted dataset. The exclusion of the repetitive identical sequences in the restricted dataset caused the different topological arrangements of the taxa at the tree and in connection with that, the tree is more explicit with the clear paraphyletic character of the sequences assigned to M. pseudodispar.

SSU rDNA sequences of the $M$. pseudodispar group have so far been obtained only from cypriniform hosts, from the Leuciscinae (A. brama, B. bjoerkna, R. rutilus and S. erythrophthalmus) and Alburninae (Alburnus alburnus). We revealed identical sequences of $M$. pseudodispar recorded in GenBank from four additional hosts: S. bulgarica, V. vimba (both Cypriniformes: Leuciscinae), P. fluviatilis and $S$. lucioperca (both Perciformes) (Fig. 3). Four new unique sequences very similar to $M$. pseudodispar sequences from GenBank and clustering within the M.pseudodispar group were acquired from tissues of L. leuciscus, L. idus, P. phoxinus (Cypriniformes: Leuciscinae) and $G$. gobio (Cypriniformes: Gobioninae).

The comparison of myxospore morphologies of M. pseudodispar and closely related Myxobolus spp. revealed that from an evolutionary point of view, there is a slight trend of change of myxospore morphology from an irregulary oval shape to oval and finally to round spores (Fig. 3). The typical irregular shape was seen in three Rutilus clades (for the fourth Rutilus clade no morphology data are available) as documented in the original description of M. pseudodispar. Oval symmetrical spores of Myxobolus spp. were obsewed in G. gobio. Sequences of this species, forming the above-mentioned Gobio clade, is very closely related to M. pseudodispar (KU340981) from A. alburnus, for which no morphology data are available.

\section{DISCUSSION}

During a large host screening of various freshwater fish species, we focused on species identity of detected Myxobolus spp. morphologically resembling Myxobolus pseudodispar, a common myxosporean parasite of cyprinid fish with pleomorphic myxospore morphology and wide host spectrum. The large diversity of species of Myxobolus together with a very simple myxospore morphology as the main taxonomic criterion is the cause of difficulties in the identification species of Myxobolus. Some myxosporeans may display a certain degree of myxospore polymorphism in the shape and size (Guo et al. 2018), which makes the myxosporean taxonomy even more problematic.

Myxobolus pseudodispar and its closely related species represent a typical example of this problem. Pleomorphic character and irregular shape of spores make difficulties in distinguishing species according to morphology and it has been suggested that $M$. pseudodispar may be a cryptic species assemblage with affinities of individual species to specific hosts (Forró and Eszterbauer 2016). Therefore, molecular taxonomy based on DNA sequences is indispensable for species determination in these cases. However, there are no exact rules for determining whether particular differences in morphology and molecular data can be used to discriminate intra- or interspecific variation in the Myxozoa.

Our SSU rDNA-based phylogenetic analysis showed differences in sequences of $M$. pseudodispar from different fish hosts and thus supported the cryptic character of different species of Myxobolus in the investigated group rather than congruence with a single species. Records of M. pseudodispar from different fish hosts represent very likely individual species of the genus Myxobolus with very similar myxospore morphology parasitising specific hosts or a specific group of fish. The SSU rDNA similarities within sequences of individual clades were more than $99 \%$, whereas interclade similarities ranged from 90.1 to $99.8 \%$, similarly as reported by Forró and Eszterbauer (2016). To find the boundary for species delimitation in the percentage of sequence similarities is often problematic. The similarity of SSU rDNA of $M$. cyprini and $M$. artus, the most closely related species in our analysis, is $99 \%$. Therefore, we assume that dissimilarity of the sequences around $1 \%$ may be the boundary to delimitate the species of Myxobolus. However, several clades have similarity higher than $99 \%$ with another clade (e.g., similarity between the Blicca/Vimba and Abramis clade), suggesting rather single species existence than existence of two independent species. Nevertheless, host specificity is still clearly evident in these clades. Using only the genetic distance criterion, at least ten new species of Myxobolus may be described in the future from the M. pseudodispar group.

Myxobolus pseudodispar was originally described as an endoparasite with developing stages in the muscle and spores scattered in different tissues of the common roach, Rutilus rutilus (see Gorbunova 1936). Phylogenetically, several different sequences identified as $M$. pseudodispar were documented from the common roach in previous studies (Molnár et al. 2002, Kallert et al. 2007, Forró and Eszterbauer 2016). We supported these sequence differences in the present study and suggested four different phylogenetic clades of M. pseudodispar in R. rutilus. Morphology and dimensions of myxobolid spores of three phylogenetic clades from the common roach correspond to the original description of M. pseudodispar by Gorbunova (1936). No morphology data are available for the fourth Rutilus clade, but its SSU rDNA shows very high similarity with the sequence of the Rutilus clade III. thus, we may predict similar morphology of myxospores of these two clades. We assume that $M$. pseudodispar firstly seen in $R$. rutilus by Gorbunova (1936) belongs to one of these four Rutilus clades, but because of the M. pseudodispar (and related species) myxospore pleomorphy and lack of additional morphological diagnostic features, it is not possible to decide which clade corresponds to the species in the original description. 
Myxobolus pseudodispar has been supposed to have a relatively wide host spectrum. At least, five closely related fish species from the Cyprinidae were reported to be infected by this parasite (e.g., Gorbunova 1936, Baska 1987, Molnár et al. 2002, Forró and Eszterbauer 2016). Our fish screening revealed another six cyprinid and two perciform fishes to be infected by Myxobolus spp. with similar morphology to $M$. pseudodispar and phylogenetically closely related to $M$. pseudodispar sequences retrieved from GenBank. However, with the knowledge of the phylogenetic clade host specificity of these Myxobolus specimens and their genetic distances, it is obvious that the host spectrum of the originally described M. pseudodispar is rather narrow. As described above, we assume that the sequence of this species fits in one of the four clades according to the type host. Only three other hosts, Abramis brama, Sander lucioperca and Scardinius erythropthalmus, were recorded as hosts for myxobolids in these four respective clades. Moreover, this myxozoan sequence was detected only once in A. brama (Baska 1987, Forró and Eszterbauer 2016) and once in Scardinius erythrophthalmus. Most of other M. pseudodispar related clades studied in the present work have also a narrow host spectrum similarly as many other species of Myxobolus, e.g., M. bejeranoi Lövy, Smirnov, Brekhman, Ofek et Lotan, 2018 from hybrid tilapia of Oreochromis aureus (Steindachner) male $\times$ Oreochromis niloticus (Linnaeus) female, or M.pseudowulii Zhang, Zhai, Liu et Gu, 2017 from the yellow catfish Pylodictis olivaris (Rafinesque) (Zhang et al. 2017, Lövy et al. 2018). The Abramis clade is the exception of the narrow host spectrum with four hosts (Abramis brama, Blicca bjoerkna, Perca fluviatilis and Sabanejewia bulgarica) detected to be infected by this myxobolid.

SSU rDNA sequences of Myxobolus pseudodispar and its closely related Myxobolus spp. (e.g., Myxobolus bartai and M. musculi Keisselitz, 1908) were obtained previously only from cyprinid hosts (Salim and Desser 2000, Molnár et al. 2002, Kent et al. 2004, Easy and Cone 2009, Iwanowicz et al. 2013, Forró and Eszterbauer 2016, Atkinson and Banner 2017, Zhang et al. 2018), specifically, from the subfamily Leuciscinae (A. brama; B. bjoerkna; Campostoma oligolepis Hubbs et Greene; Gila coerulea [Girard]; Luxilus cornutus [Mitchill]; Ptychocheilus oregonensis [Richardson]; R. rutilus and S. erythrophthalmus), Cyprininae (Carassius gibelio [Bloch]; Cyprinus carpio Linnaeus); Labeoninae (Labeo rohita [Hamilton]; Osteochilus vittatus [Valenciennes]), Barbinae (Luciobarbus bocagei [Steindachner]) and Alburninae (Alburnus alburnus).

These myxobolids form a diverse group of muscle-infecting Myxobolus spp. within a large subclade VIII according to Liu et al. (2019), which is specific for the Cypriniformes. Among newly identified hosts for M. pseudodispar, there are mostly cyprinids from the subfamily Leuciscinae (S. bulgarica; Vimba vimba; Leuciscus leuciscus; Leuciscus idus; Phoxinus phoxinus) and newly from the subfamily Gobioninae (Gobio gobio). Interestingly, we detected, by PCR and identified by sequencing, these myxobolids from two perciform fish $P$. fluviatilis and $S$. lucioperca. Myxobolus pseudodispar identified in P. flu- viatilis (identical with M. pseudodispar GenBank AccNo. AF466649) was also detected in other three cyprinid fish species suggesting a wide host spectrum for the M. pseudodispar group which was broadened by host switching and adaptation even to a phylogenetically more distant host from Perciformes. However, no spores or development stages of Myxobolus were microscopically determined in these two perciform hosts. Hence, the presence of M. pseudodispar in P. fluviatilis and S. lucioperca may be also explained by the occurrence of these species in accidental hosts and a blind at by of the parasite development.

The prevalence of $M$. pseudodispar was higher (67\%; 28/40) in the type host ( $R$. rutilus) in the present work in comparison with $41 \%$ recorded in Molnár et al. (2010) and much higher than $17 \%, 0.4 \%$ and $19 \%$, respectively, which were recorded by Athanassopoulou and Sommerville (1993). At very high prevalence (94\%) was documented by Forró and Eszterbauer (2016) after experimental exposure, which likely does not correlate with levels of natural infection. Discrepancies in different levels of prevalence can be explained by different localities under study, different age of screened fish or different sampling time of the year. The screening methodology is also very important for the prevalence analysis. PCR is very sensitive and detects also microscopically undetectable infections (Grossel et al. 2005). In our study, we derived the prevalence from combination of light microscopy, PCR and sequencing, which is likely the reason for higher prevalence values we observed for compared to these based only on the microscopical examination. The highest prevalence, interestingly, was detected in vimba bream $V$. vimba $(86 \% ; 6 / 7)$ and in common minnow $P$. phoxinus $(65 \% ; 11 / 17)$, the hosts in which $M$. pseudodispar has never been observed.

Type of locality and geographic origin of the samples do not seem to have an influence on the phylogenetic relationships within the species of $M$. pseudodispar complex. Samples in the present study were obtained from three different locality types (pond, reservoir and river/brook) and from two different countries: Czech Republic (ponds, reservoirs, rivers) and Bulgaria (Danube River). Several sequences from identical hosts but different localities were found to be identical, e.g., Myxobolus sp. SSU rDNA sequences from $V$. vimba from the pond in Vodňany $(\mathrm{CZ})$ and from the Danube River in Bulgaria revealed 100\% sequence identity. In addition to that, several sequences from the samples from the same geographic locality and the same host, e.g.: M. pseudodispar from $R$. rutilus from Švihov Reservoir (CZ), clustered in different lineages at the phylogenetic tree with similarity around $96 \%$. This may be due to the ability of $M$. pseudodispar to infect several oligochaete host species (Marton and Eszterbauer 2012) and thus the observed diversity of Myxobolus may be the result of co-evolution of a definitive host and its parasite.

The evolutionary success of the species of Myxobolus diversity is obvious and has been documented many times (recently reviewed in Liu et al. 2019). We proved that M. pseudodispar is a complex of closely related species that parasitise not only in the different hosts but also in different host tissues as the spores were observed frequently 
out of muscles, where the development of plasmodia was documented (e.g., Gorbunova 1936, Gonzalez-Lanza and Alvarez-Pellitero 1985, Baska 1987). Myxobolus pseudodispar is a typical example of a great ability of myxozoans to speciate after adapting to new hosts either by host switching or by host-parasite coevolutionary processes.

Acknowledgemets. The authors thank colleagues from Fish Ecology Unit of the Department of Fish and Zooplankton Ecology, Institute of Hydrobiology, Biology Centre of the Czech Academy of Sciences, České Budějovice (www.fishecu.cz), Czech Anglers Union, local authorities of Golčův Jeníkov, Teodora Trichkova,
Milcho Todorov (Institute of Biodiversity and Ecosystem Research of the Bulgarian Academy of Sciences), Libor Mikl, Václav Prášek (Institute of Vertebrate Biology of the Czech Academy of Sciences, Brno) for their assistance in fish collection and Alena Lövy (Institute of Parasitology, Biology Centre of the Czech Academy of Sciences, Ceské Budějovice), for her assistance in fish dissection. Financial support was provided by the Czech Science Foundation (project No. 19-28399X), the project QK1920011 "Methodology of predatory fish quantification in drinking-water reservoirs to optimise the management of aquatic ecosystems" and ERDF/ESF project "Biomanipulation as a tool for improving water quality of dam reservoirs" (No. CZ.02.1.01/0.0/0.0/16_025/0007417).

\section{REFERENCES}

Andree K.B., Székely C., Molnár K., Gresoviac S.J., HEDRICK R.P. 1999: Relationships among members of the genus Myxobolus (Myxozoa: Bilvalvidae) based on small subunit ribosomal DNA sequences. J. Parasitol. 85: 68-74.

Athanassopoulou F., Sommerville C. 1993: The significance of myxosporean infections in roach, Rutilus rutilus L., in different habitats. J. Fish Dis. 16: 39-51.

Atkinson S.D., BAnner C.R. 2017: A novel myxosporean parasite Myxobolus klamathellus n. sp. (Cnidaria: Myxosporea) from native blue chub (Gila coerulea) in Klamath Lake, Oregon. Parasitol. Res. 11: 299-302.

BARToŠová P., Fiala I. 2011: Molecular evidence for the existence of cryptic species assemblages of several myxosporeans (Myxozoa). Parasitol. Res. 108: 573-583.

Bartošová-Sojková P., Hrabcová M., Pecková H., Patra S., Kodádková A., Jurajda P.,Tyml T., Holzer A.S. 2014: Hidden diversity and evolutionary trends in malacosporean parasites (Cnidaria: Myxozoa) identified using molecular phylogenetics. Int. J. Parasitol. 44: 565-577.

BASKA F. 1987: Histological studies on the development of Myxobolus pseudodispar Gorbunova, 1936 in the roach (Rutilus rutilus). Acta Vet. Hung. 35: 251-257.

Boore J.L., Brown W.M. 2000: Mitochondrial genomes of Galathealinum, Helobdella, and Platynereis: sequence and gene arrangement comparisons indicate that Pogonophora is not a phylum and Annelida and Arthropoda are not sister taxa. Mol. Biol. Evol. 17: 87-106.

Carriero M.M., Adriano E.A., Silva M.R., Ceccarelli P.S., MaiA A.A. 2013: Molecular phylogeny of the Myxobolus and Henneguya genera with several new South American species. PLoS ONE 8: e73713.

EAsy R., Cone D. 2009: Taxonomy of Myxobolus ridouti n. sp. and $M$. ridgwayi n. sp. (Myxozoa) from Pimephales notatus and Semotilus atromaculatus (Cypriniformes) in Ontario. J. Parasitol. 95: 1446-1451.

Eiras J.C., Molnár K., Lu Y.S. 2005: Synopsis of the species of Myxobolus Bütschli, 1882 (Myxozoa: Myxosporea: Myxobolidae). Syst. Parasitol. 61: 1-46.

Eiras J.C., Zhang J., Molnár K. 2014: Synopsis of the species of Myxobolus Bütschli, 1882 (Myxozoa: Myxosporea, Myxobolidae) described between 2005 and 2013. Syst. Parasitol. 88: 11-36.

EszTERBAUER E. 2004: Genetic relationship among gill-infecting Myxobolus species (Myxosporea) of cyprinids: molecular evidence of importance of tissue-specificity. Dis. Aquat. Org. 58: 35-40.

Eszterbauer E., Benkó M., Dán Á., Molnár K. 2001: Identification of fish-parasitic Myxobolus (Myxosporea) species using a combined PCR-RFLP method. Dis. Aquat. Org. 44: 35-39.

FiAla I. 2006: The phylogeny of Myxosporea (Myxozoa) based on small subunit ribosomal RNA gene analysis. Int. J. Parasitol. 36: 1521-1534.
Fiala I., BARToŠová P. 2010: History of myxozoan character evolution on the basis of rDNA and EF-2 data. BMC Evol. Biol. 10: 228.

Fiala I., Bartošová-Sojková P., Whipps C.M. 2015: Classification and phylogenetics of Myxozoa. In: B. Okamura, A. Gruhl, J.L. Bartholomew (Eds.), Myxozoan Evolution, Ecology and Development. Springer International Publishing, Cham, pp. 85-110.

Folefack G.B.L., Abdel-Baki A.A.S., Ateba N.O.O., Fomena A., Mansour L. 2019: Morphological and molecular characterization of Myxobolus dibombensis sp. n. (Myxozoa: Myxobolidae), a parasite of the African carp Labeobarbus batesii (Teleostei: Cyprinidae) from Dibombe River, Cameroon. Parasitol. Res. 118: 1-9.

Forró B., Eszterbauer E. 2016: Correlation between host specificity and genetic diversity for the muscle-dwelling fish parasite Myxobolus pseudodispar: examples of myxozoan host-shift? Folia Parasitol. 63: 1.

Gilbert M.A., Granath W.O. 2003: Whirling disease of salmonid fish: life cycle, biology and disease. J. Parasitol. 89: 658-667.

Gonzalez-Lanza M.C., Alvarez-Pellitero M.P. 1985: Myxobolus spp. of various cyprinids from the River Esla (León, NW Spain). Description and population dynamics. Angew. Parasitol. 26: 71-83.

Gorbunova M. 1936: Changes in the parasitic fauna of pike and roach according to their age. Uchenye Zapiski Leningradskogo Ordena Lenina Gosudarstvennogo Universiteta, No. 7 (Biol. Ser.), Fasc. 3, Problems of Economical Parasitology, Leningrad, pp. 5-30. (In Russian).

Grossel G., Handlinger J., Battaglene S., Munday B. 2005 Diagnostic polymerase chain reaction assay to detect Kudoa neurophila (Myxozoa: Multivalvulida) in a marine finfish hatchery. Dis. Aquat. Org. 64: 141-149.

Guo Q., Huang M., Liu Y., Zhang X., Gu Z. 2018: Morphological plasticity in Myxobolus Bütschli, 1882: a taxonomic dilemma case and renaming of a parasite species of the common carp. Parasit. Vector. 11: 399

Hallett S.L., Diamant A. 2001: Ultrastructure and small-subunit ribosomal DNA sequence of Henneguya lesteri n. sp. (Myxosporea), a parasite of sand whiting Sillago analis (Sillaginidae) from the coast of Queensland, Australia. Dis. Aquat. Org. 46: 197-212.

Hartikainen H., Bass D., Briscoe A.G., Knipe H., Green A.J., OKamura B. 2016: Assessing myxozoan presence and diversity using environmental DNA. Int. J. Parasitol. 46: 781-792.

Hedrick R.P., MacConnell E., De Kinkelin P. 1993: Proliferative kidney disease of salmonid fish. Annu. Rev. Fish Dis. 3: 277-290.

Hillis D.M., Dixon, M.T. 1991: Ribosomal DNA: molecular evolution and phylogenetic inference. Q. Rev. Biol. 66: 411-453.

Holzer A.S., Bartošová P., Pecková H., Tyml T., Atkinson S., Bartholomew J., Sipos D., Eszterbauer E., Dyková, I. 2013: 'Who's who' in renal sphaerosporids (Bivalvulida: Myxo- 
zoa) from common carp, Prussian carp and goldfish - molecular identification of cryptic species, blood stages and new members of Sphaerospora sensu stricto. Parasitology 140: 46-60.

Holzer A.S., Bartošová-Sojková P., Born-Torrijos A., Lövy A., Hartigan A., Fiala I. 2018: The joint evolution of the Myxozoa and their alternate hosts: a cnidarian recipe for success and vast biodiversity. Mol. Ecol. 27: 1651-1666.

Holzer A.S., Sommerville C., Wootten R. 2004: Molecular relationships and phylogeny in a community of myxosporeans and actinosporeans based on their $18 \mathrm{~S}$ rDNA sequences. Int. J. Parasitol. 34: 1099-1111.

Iwanowicz D.D., Iwanowicz L.R., Howerth E.W., Schill W.B., Blazer V.S., Johnson R.L. 2013: Characterization of a new myxozoan species (Myxozoa: Myxobolidae: Myxosporea) in largescale stonerollers (Campostoma oligolepis) from the Mobile River Basin (Alabama). J. Parasitol. 99: 102-112.

Kallert D.M., Ponader S., Eszterbauer E., El-Matboul M., HaAs W. 2007: Myxozoan transmission via actinospores: new insights into mechanisms and adaptations for host invasion. Parasitology 134: 1741-1750.

Katoh K., Kuma K.I., Тон H., Miyata T. 2005: MAFFT version 5: improvement in accuracy of multiple sequence alignment Nucl. Acids Res. 33: 511-518.

Kearse M., Moir R., Wilson A., Stones-Havas S., Cheung M., Sturrock S., Buxton S., Cooper A., Markowitz S., Duran C., Thierer T., Ashton B., Meinties P., Drummond A. 2012: Geneious Basic: an integrated and extendable desktop software platform for the organization and analysis of sequence data. Bioinformatics 28: 1647-1649.

Kent M.L., Andree K.B., Bartholomew J.L., El-Matbouli M., Desser S.S, Devlin R.H., Feist S.W., Hedrick R.P., Hoffmann R.W., Khattra J., Hallett S.L., Lester R.J.G., Longshaw M., Palenzuala O., Siddall M.E., Xiao C. 2001: Recent advances in our knowledge of the Myxozoa. J. Eukaryot. Microbiol. 48: 395-413.

Kent M.L., Traxler G.S., Kieser D., Richard J., Dawe S.C., Shaw R.W., Prosperi-Porta G., Ketcheson J., Evelyn T.P.T. 1998: Survey of salmonid pathogens in ocean-caught fishes in British Columbia, Canada. J. Aquat. Anim. Health 10: 211-219.

Kent M.L., Watral V.G., Whipps C.M., Cunningham M.E., Criscione C.D., Heidel J.R., Curtis L.R., Spitsbergen J., MARKLE D.F. 2004: A digenean metacercaria (Apophallus sp.) and a myxozoan (Myxobolus sp.) associated with vertebral deformities in cyprinid fishes from the Willamette River, Oregon. J. Aquat. Anim. Health 16: 116-129.

LiU Y., Lövy A., Gu Z., Fiala I. 2019: Phylogeny of Myxobolidae (Myxozoa) and the evolution of myxospore appendages in the Myxobolus clade. Int. J. Parasitol. 49: 523-530.

Lövy A., Smirnov M., Brekhman V., Ofek T., Lotan T. 2018: Morphological and molecular characterization of a novel myxosporean parasite Myxobolus bejeranoi n. sp. (Cnidaria: Myxosporea) from hybrid tilapia in Israel. Parasitol. Res. 117: 491-499.

Lom J., Dyková I. 1992: Protozoan Parasites of Fishes. Elsevier, New York, $315 \mathrm{pp}$.

Loм J., Dyкоvé I. 2006: Myxozoan genera: definition and notes on taxonomy, life-cycle terminology and pathogenic species. Folia Parasitol. 53: 1-36.

Marton S., Eszterbauer E. 2012: The susceptibility of diverse species of cultured oligochaetes to the fish parasite Myxobolus pseudodispar Gorbunova (Myxozoa). J. Fish Dis. 35: 303-314.

Molnár K., Eszterbauer E., Székely C., Dán Á., Harrach B. 2002: Morphological and molecular biological studies on intramuscular Myxobolus spp. of cyprinid fish. J. Fish Dis. 25 : 643-652.
Molnár K., Marton S., Székely C., Eszterbauer E. 2010: Differentiation of Myxobolus spp. (Myxozoa: Myxobolidae) infecting roach (Rutilus rutilus) in Hungary. Parasitol. Res. 107: $1137-1150$.

Okamura B., Gruhl A., Bartholomew J.L. 2015: An introduction to myxozoan evolution, ecology and development. In: B. Okamura, A. Gruhl, J.L. Bartholomew (Eds.), Myxozoan Evolution, Ecology and Development. Springer International Publishing, Cham, pp. 1-20.

Okamura B., Hartigan A., Naldoni, J. 2018: Extensive uncharted biodiversity: the parasite dimension. Integr. Comp. Biol. 58: 1132-1145.

Posada D. 2008: jModelTest: phylogenetic model averaging. Mol. Biol. Evol. 25: 1253-1256.

Rocha S., Azevedo C., Oliveira E., Alves A., Antunes C., Rodrigues P., CAsal G. 2019: Phylogeny and comprehensive revision of mugiliform-infecting myxobolids (Myxozoa, Myxobolidae), with the morphological and molecular redescription of the cryptic species Myxobolus exiguus. Parasitology 146: 479-496.

RonQuist F., Huelsenbeck J.P. 2003: MrBayes 3: Bayesian phylogenetic inference under mixed models. Bioinformatics 19: 1572-1574.

Salim K.Y., Desser S.S. 2000: Descriptions and phylogenetic systematics of Myxobolus spp. from cyprinids in Algonquin Park, Ontario. J. Eukaryot. Microbiol. 47: 309-318.

Shimodaira H., Hasegawa M. 2001: CONSEL: for assessing the confidence of phylogenetic tree selection. Bioinformatics 17: $1246-1247$

Stamatakis A. 2006: RAxML-VI-HPC: maximum likelihood-based phylogenetic analyses with thousands of taxa and mixed models. Bioinformatics 22: 2688-2690.

Stöver B.C., Müller K.F. 2010: TreeGraph 2: combining and visualizing evidence from different phylogenetic analyses. BMC Bioinform. 11: 7.

SWOFFORD D.L. 2001: PAUP*: phylogenetic analysis using parsimony, version 4.0b10. Sinauer Associates, Sunderland, Massachusetts.

SzÉKely C., Molnár K., RÁCz O. 2001: Complete developmental cycle of Myxobolus pseudodispar (Gorbunova) (Myxosporea: Myxobolidae). J. Fish Dis.: 24, 461-468.

Székely C., Shaharom-Harrison F., Cech G., Ostoros G., MolnáR K. 2009: Myxozoan infections in fishes of the Tasik Kenyir water reservoir, Terengganu, Malaysia. Dis. Aquat. Org. 83: 37-48.

Zhang B., Zhai Y., Gu Z., LiU Y. 2018: Morphological, histological and molecular characterization of Myxobolus kingchowensis and Thelohanellus cf. sinensis infecting gibel carp Carassius auratus gibelio (Bloch, 1782). Acta Parasitol. 63: 221-231.

Zhang B., Zhai Y., LiU Y., Gu, Z. 2017: Myxobolus pseudowulii sp. n. (Myxozoa: Myxosporea), a new skin parasite of yellow catfish Tachysurus fulvidraco (Richardson) and redescription of Myxobolus voremkhai (Akhmerov, 1960). Folia Parasitol. 64: 030.

Zhang J.Y., Yokoyama H., Wang J.G., Li A.H., Gong X.N., Ryu-Hasegawa A., Iwashita M., Ogawa K. 2010: Utilization of tissue habitats by Myxobolus wulii Landsberg \& Lom, 1991 in different carp hosts and disease resistance in allogynogenetic gibel carp: redescription of $M$. wulii from China and Japan. J. Fish Dis. 33: 57-68.

Zhang X., Liu Y., Whipps C.M., Guo Q., Gu Z. 2019: Multiple evolutionary routes of the single polar capsule in Thelohanellus species (Myxozoa: Myxobolidae). Int. J. Parasitol. Parasites Wildl. 8: 56-62. 